\title{
Review: Impact of food, gut-brain signals and metabolic status on brain activity in the pig model: 10 years of nutrition research using in vivo brain imaging
}

\author{
D. Val-Laillet $\odot$ \\ INRA, INSERM, Univ Rennes, Nutrition Metabolisms and Cancer, NuMeCan, Rennes, St Gilles, France
}

(Received 13 February 2019; Accepted 4 July 2019; First published online 29 July 2019)

\begin{abstract}
The purpose of this review is to offer a panorama on 10 years of nutrition research using in vivo brain imaging in the pig model. First, we will review some work describing the brain responses to food signals, including basic tastants such as sweet and bitter at both oral and visceral levels, as well as conditioned preferred and aversive flavours. Second, we will have a look at the impact of weight gain and obesity on brain metabolism and functional responses, drawing the parallel with obese human patients. Third, we will evoke the concept of the developmental origins of health and diseases, and how the pig model can shed light on the importance of maternal nutrition during gestation and lactation for the development of the gut-brain axis and adaptation abilities of the progeny to nutritional environments. Finally, three examples of preventive or therapeutic strategies will be introduced: the use of sensory food ingredients or pre-, pro-, and postbiotics to improve metabolic and cognitive functions; the implementation of chronic vagus nerve stimulation to prevent weight gain and glucose metabolism alterations; and the development of bariatric surgery in the pig model for the understanding of its complex mechanisms at the gut-brain level. $A$ critical conclusion will brush the limitations of neurocognitive studies in the pig model and put in perspective the rationale and ethical concerns underlying the use of pig experimentation in nutrition and neurosciences.
\end{abstract}

Keywords: nutrition, microbiota, cognition, pleasure, behaviour

\section{Implications}

The purpose of this review is to offer a panorama on 10 years of nutrition research using in vivo brain imaging in the pig model, and to improve the understanding of the gut-brain axis factors modulating brain activity. This research has implications in the context of animal and human nutrition and health, covering the scope of animal production as well as translational medicine. In addition to the original insight these provide in neurocognitive and developmental sciences, the scientific studies presented here are valuable for the development of new preventive, diagnosis and therapeutics solutions to fight against nutritional and behavioural disorders.

\section{Introduction}

The present review is dedicated to the exploration of brain activity via in vivo brain imaging in the pig model, in the context of nutrition and metabolic research, and to the understanding of the gut-brain axis factors modulating this brain

E-mail: david.val-laillet@inra.fr activity. Brain activity is a rather imprecise phrasing encompassing several meanings and embracing different concepts. Throughout this review, the terms 'brain activity' will be used as an ellipsis referring to neurobiological outcomes, which can be visualized via brain imaging techniques such as nuclear brain tomography or functional magnetic resonance imaging (fMRI). Using these brain imaging techniques, we can investigate cerebral blood flow, brain glucose metabolism, or the blood-oxygen-level-dependent (BOLD) haemodynamic response, all of those being correlated with neural activity and integration processes. Brain activity or metabolism can be visualized in a resting state, or in response to specific stimulations and sensory-cognitive tasks.

Nutrition research in the conventional or miniature pig is justified by a two-way rationale: first, the (mini)pig is a farm (or pet) animal that is bred and raised to provide human food resources (or company); second, the pig is probably the closest animal to human beings in terms of digestive physiology (Guilloteau et al., 2010; Roura et al., 2016), and it shares many other similarities with the human. Similarities include a relatively large gyrencephalic brain (Sauleau et al., 2009; Roura et al., 2016) associated with high cognitive abilities 
(Dilger and Johnson, 2010), which is why the pig is a very good preclinical research model in nutrition and neurobehavioral disorders (Lind et al., 2007; Gieling et al., 2011). Improving the health and well-being of farm (and pet) animals is not only a legal and ethical responsibility, but also a prerequisite to food quality and human health. Understanding how nutrition can modify the pig's physiology, gut microbiota, metabolism, behaviour and health, within the spectrum of comparative pathology, is highly valuable to gain knowledge in human nutrition and health, and fight against food-related metabolic and behavioural disorders in both species.

The role of the microbiota-gut-brain axis in processing information and nutrients, as well as in regulating digestive processes and eating behaviour, has been well documented and still attracts interest (van de Wouw et al., 2017). The brain is the conductor of almost all biological functions and behaviour, including eating behaviour and digestion. The way the brain responds to food/metabolic status and integrates information shapes the nutritional and emotional status of the individual, the satiety-hunger alternation, the perception of pleasure and the emergence of goal-oriented behaviours. On this gut-brain communication depends the individual's ability to adapt to its nutritional environment, by making choices and decisions that impact health and well-being. Investigating brain activity in response to food or diet is not only a fascinating fundamental research topic but also a pathway to applied and translational research to the benefit of animal and human health.

Different ways of tackling this topic in the pig will be presented. First, the implementation of functional and metabolic imaging in the pig model can be used to investigate the brain responses to food exteroceptive and interoceptive perception, in the context of hedonic, homeostatic or cognitive processes. Second, investigating brain activity in swine opens the way to understanding how metabolic diseases and eating disorders are linked to diet-related neurocognitive anomalies. Many studies showed that the minipig model is a real asset to investigate obesity and metabolic syndrome (e.g. Johansen et al., 2001). This question can be explored in adult animals with a declared pathology, but also before the onset of the disease, during sensitive periods such as the perinatal life. The relatively short developmental period and lifespan of pigs, compared to humans, is consequently a unique opportunity to decipher the nutritional events/status shaping brain functions from birth to the adult age. Finally, brain imaging can be used to assess the impact of preventive or therapeutic strategies in preclinical studies. In this review, the case of functional food ingredients, neurostimulation and bariatric surgery will be evoked.

Table 1 and Figure 1 summarize 10 years of collective work in nutrition research using in vivo brain imaging in the pig model by the St Gilles INRA group. Specifically, the author would like to individually acknowledge CharlesHenri Malbert for his outstanding contribution to the development of nuclear brain imaging in the pig model, as well as Nicolas Coquery and Hervé Saint-Jalmes for the implementation of pig fMRI on the PRISM imaging platform. In addition to published references, a few unpublished data have been included in this review to illustrate the more recent questions and perspectives currently investigated by our group.

\section{Brain responses to food signals}

\section{Brain responses to basic tastes}

The brain integrates a huge amount of information coming from the environment and the inside of the organism, through different communication pathways. Exposure to food and their post-ingestive consequences generates both exteroceptive (e.g. smell, taste, vision) and interoceptive (i.e. gut perceptions) signals that the brain must integrate and associate to elaborate a multisensory mental representation of food items. This mental representation includes physical and hedonic dimensions depending on the individual experience shaping individual expectations. One of our first objectives was consequently to map the brain responses to basic tastants, such as sweet or bitter compounds, which are known to elicit strong innate appetitive or repulsive reactions (Steiner et al., 2001). The role of gut nutrient sensing in modulating appetite and conditioning food preferences (notably via sugar gut infusions) has also been extensively described (Sclafani and Ackroff, 2012). For sweet/sugar perception, our first question was to elucidate whether the detection site might condition the brain responses elicited. Glucose portal infusion (Figure 1e) and duodenal infusion (Figure 1d) both reduced feed intake and ingestion speed in a similar way, but induced different systemic signals and different brain responses (Table 1; Boubaker et al., 2012), which demonstrates that gut nutrient and/or taste perception can shape brain responses related to hedonic and homeostatic regulation of food intake in the pig. The next step was to compare exteroceptive (i.e. gustatory) and interoceptive (i.e. duodenal) perceptions of sweet taste/nutrient, and more precisely to compare the impact of combined $v$. dissociated oral and intestinal sucrose detection, on the brain reward processes. Oral and/or duodenal sucrose sensing (Figure 1c and d) induced differential cerebral blood flow changes in brain regions, known to be involved in memory, reward processes and hedonic evaluation of sensory stimuli (Table 1; Clouard et al., 2014). Such information is valuable to disentangle the respective roles of oral and visceral perception of sweet/sugar in modulating food intake and motivation, and for translational research using the pig model - for example, to assess the impact of additives or artificial sweeteners, design new food products or improve their nutritional quality with a benefitsrisks approach in terms of palatability, health, gut-brain axis and behaviour.

More recently, using fMRI, we aimed to compare oral sweet and bitter gustatory stimulation (Table 1; Coquery et al., 2018). The advantage of fMRI for comparing brain responses to different food stimuli is that multiple 
Table 1 Summary of 10 years of nutrition research (2008 to 2018) using in vivo brain imaging in the conventional pig ([Large White $\times$ Landrace] $\times$ Piétrain) and minipig models

\begin{tabular}{|c|c|c|c|c|c|}
\hline No. & Pig models & $\begin{array}{c}\text { Type of food-related sensory stimulation } \\
\text { and/or dietary treatment }\end{array}$ & $\begin{array}{l}\text { In vivo brain imaging } \\
\text { modalities }\end{array}$ & Research highlights & References \\
\hline 1 & $\begin{array}{l}\text { 3-month-old, female growing } \\
\text { conventional pigs }\end{array}$ & Chronic VNS during 5 weeks & 99mTc-HMPAO SPECT & $\begin{array}{l}\text { VNS triggered brain plasticity in subcortical } \\
\text { structures of the reward circuit and activated } \\
\text { the olfactory bulb }\end{array}$ & Biraben et al. (2008) \\
\hline 2 & $\begin{array}{l}\text { 3-month-old, female growing } \\
\text { conventional pigs }\end{array}$ & $\begin{array}{l}\text { Gastric distension in animals with intact vagal } \\
\text { nerves or bilateral Vagotomy }\end{array}$ & 99mTc-HMPAO SPECT & $\begin{array}{l}\text { Before vagotomy, significant brain activity } \\
\text { associated with increase of gastric distending } \\
\text { pressure; after vagotomy, only a limited effect } \\
\text { of increased gastric pressure on brain activity }\end{array}$ & Sauleau et al. (2009) \\
\hline 3 & $\begin{array}{l}\text { 3.5-month-old, female growing } \\
\text { conventional pigs }\end{array}$ & $\begin{array}{l}\text { Olfactogustatory stimulation during brain } \\
\text { imaging with different flavours previously } \\
\text { associated with positive or negative post- } \\
\text { ingestive consequences }\end{array}$ & 99mTc-HMPAO SPECT & $\begin{array}{l}\text { Higher activity in corticolimbic and reward- } \\
\text { related areas with preferred flavour/ } \\
\text { deactivation of the basal nuclei and limbic } \\
\text { thalamic nuclei with aversive flavour }\end{array}$ & Gaultier et al. (2011) \\
\hline 4 & $\begin{array}{l}\text { Normal-weight or obese, } \\
\text { 2.5-year-old, male } \\
\text { Göttingen minipigs }\end{array}$ & $\begin{array}{l}\text { 5-month exposure to standard diet (SD; } 102 \\
\mathrm{kcal} / \mathrm{kg}^{0.75} \text { ) or ad libitum Western diet (WD) }\end{array}$ & 99mTc-HMPAO SPECT & $\begin{array}{l}\text { Deactivation of the prefrontal cortex, ventral } \\
\text { tegmental area and nucleus accumbens in } \\
\text { obese compared to lean subjects/prefrontal } \\
\text { cortex and insular cortex activity negatively } \\
\text { associated with BW }\end{array}$ & Val-Laillet et al. (2011b) \\
\hline 5 & $\begin{array}{l}\text { Obese, adult Pitman-Moore } \\
\text { minipigs }\end{array}$ & $\begin{array}{l}\text { 5-week exposure to isocaloric high-energy } \\
\text { high-fat diets enriched either with fish } \\
\text { oil (n-3), sunflower oil (n-6) or lard } \\
\text { (saturated fat, S) }\end{array}$ & $\begin{array}{l}\text { 18FDG PET/dynamic injected } \\
\text { CT-scan to map BBB } \\
\text { permeability }\end{array}$ & $\begin{array}{l}\text { Anterior prefrontal cortex metabolism lesser for } \\
n-3 \text {, intermediary for } S \text { and higher for } n-6 / \\
\text { decreased activity in the nucleus accumbens } \\
\text { for } n-3 \text { compared to } n-6 / B B B \text { the most } \\
\text { permeable in } n-3 \text {, intermediary in } S \text { and the } \\
\text { least permeable in } n-6 \text { in cortical areas/ } \\
\text { correlation between BBB permeability and } \\
\text { prefrontal cortex activity }\end{array}$ & $\begin{array}{l}\text { Val-Laillet et al. (2011a and } \\
\text { 2013) (conference } \\
\text { proceedings) }\end{array}$ \\
\hline 6 & $\begin{array}{l}\text { 3-month-old, female growing } \\
\text { conventional pigs }\end{array}$ & $\begin{array}{l}\text { Duodenal or portal glucose } 20 \% \text { (120 ml in } \\
10 \mathrm{~min} \text { ) infusion after overnight fasting }\end{array}$ & 99mTc-HMPAO SPECT & $\begin{array}{l}\text { Both duodenal and portal glucose activated } \\
\text { dorsolateral prefrontal cortex and primary } \\
\text { somatosensory cortex/duodenal glucose } \\
\text { activated pyriform area, orbitofrontal cortex, } \\
\text { caudate and putamen/portal glucose activated } \\
\text { insular cortex }\end{array}$ & Boubaker et al. (2012) \\
\hline 7 & $\begin{array}{l}\text { 3.5-month-old, female } \\
\text { growing conventional pigs }\end{array}$ & $\begin{array}{l}\text { Olfactogustatory stimulation during brain } \\
\text { imaging with different flavours previously } \\
\text { associated with positive or negative post- } \\
\text { ingestive consequences }\end{array}$ & 18FDG PET & $\begin{array}{l}\text { Aversive or less preferred flavours deactivated } \\
\text { prefrontal cortex, activated posterior cingulate } \\
\text { cortex and induced asymmetric brain } \\
\text { responses in basal nuclei and temporal gyrus }\end{array}$ & Clouard et al. (2012c) \\
\hline
\end{tabular}

ingestive consequences

responses in basal nuclei and temporal gyrus 


\section{No. Pig models}

8 3.5-month-old, female growing Oral (5\% sucrose or artificial saliva) and/or conventional pigs duodenal $(16 \%$ sucrose or saline, $300 \mathrm{ml})$ sucrose stimulation after overnight fasting

9 Obese, 20-month-old male

7-month exposure to a high-energy high-fat and female Yucatan minipigs

fructose - all diets were isocaloric (1 kg/day)

8FDG PET

10 2-month-old, female growing Olfactogustatory stimulation with food flavour conventional pigs

with or without functional sensory additive in animals that were habituated or not to this additive since weaning

11 3-month-old, female growing conventional pigs

12 Normal-weight and obese, 18-month-old Yucatan minipigs

15-day chronic abdominal vagal electrical stimulation with three different procedures: a long-lasting $1000-\mu$ s pulse (S1), a series of constant-amplitude pulsons lasting $1000 \mu \mathrm{s}$ (S2) and a series of pulsons with rising amplitude also lasting $1000 \mu \mathrm{s}$ (S3)

12-week chronic abdominal vagal electrical stimulation in obese minipigs compared to sham obese and sham normal weight

13 3.5-month-old, female growing 3-week exposure to water beverage with or conventional pigs

modalities

18FDG PET

18FDG PET
In vivo brain imaging

99mTc-HMPAO SPECT

Research highlights

References

Duodenal sucrose and combined oral/duodenal sucrose induced similar activity patterns in the putamen, ventral anterior cingulate cortex and hippocampus/oral sucrose deactivated some brain areas in the prefrontal and insular cortices/combined oral/duodenal sucrose activated right insular cortex and oral sucrose dissociated from caloric load-induced specific activity patterns in hippocampus and parahippocampal cortex

Compared to starch, chronic exposure to fructose and glucose induced bilateral brain activations in anterior and dorsolateral prefrontal cortex, orbitofrontal cortex, anterior cingulate cortex, caudate and putamen Familiar feed flavours activated the prefrontal cortex/amygdala, insular cortex and prepyriform area were only activated in familiarized animals exposed to the feed flavour with additive/perception of feed flavour with additive in the familiarized animals activated the dorsal striatum differently than perception of control feed flavour in naive animals

Both S2 and S3 activated the dorsal vagal complex and increased the metabolism of different afferent cortical structures, notably the insular, prefrontal and cingulate cortices

Vagal stimulation was associated with increased Malbert et al. (2017a) glucose metabolism in the cingulate and prefrontal cortices

Sodium butyrate compared with control treatment triggered basal brain glucose metabolism changes in nucleus accumbens and hippocampus, increased hippocampal granular cell layer volume and neurogenesis
Ochoa et al. (2016a)

Val-Laillet et al. (2016)

Malbert et al. (2017b)

Val-Laillet et al. (2018) 
Table 1 (Continued)

\begin{tabular}{|c|c|c|c|c|c|}
\hline No. & Pig models & $\begin{array}{c}\text { Type of food-related sensory stimulation } \\
\text { and/or dietary treatment }\end{array}$ & $\begin{array}{l}\text { In vivo brain imaging } \\
\text { modalities }\end{array}$ & Research highlights & References \\
\hline 14 & $\begin{array}{l}\text { Normal-weight, 18-month-old } \\
\text { male and female Yucatan } \\
\text { minipigs }\end{array}$ & $\begin{array}{l}\text { Animals that were born from mothers fed either } \\
\text { a SD or a WD during gestation and lactation }\end{array}$ & $\begin{array}{l}\text { [123I]-FP-CIT SPECT (aka } \\
\text { DaTscan) to map brain } \\
\text { availability of presynaptic } \\
\text { dopamine (and serotonin) } \\
\text { transporter/18FDG PET }\end{array}$ & $\begin{array}{l}\text { At adult age, WD progeny showed lower } \\
\text { dopamine/serotonin transporter binding } \\
\text { potential in hippocampus and } \\
\text { parahippocampal cortex, as well as a trend in } \\
\text { putamen, associated with lower basal brain } \\
\text { activity in prefrontal cortex and nucleus } \\
\text { accumbens compared to SD progeny }\end{array}$ & Gautier et al. (2018) \\
\hline 15 & $\begin{array}{l}\text { 18-month-old Yucatan } \\
\text { minipigs }\end{array}$ & $\begin{array}{l}\text { Gustatory stimulation with artificial saliva, } \\
\text { quinine }(10 \mathrm{mM}) \text { or sucrose }(5 \%) \text { after an } \\
\text { overnight fasting }\end{array}$ & fMRI & $\begin{array}{l}\text { Quinine and sucrose stimulation promoted } \\
\text { different cerebral activation patterns/insular } \\
\text { cortex was activated with both sucrose and } \\
\text { quinine, although some other regions were } \\
\text { specifically activated by sucrose or quinine }\end{array}$ & Coquery et al. (2018) \\
\hline 16 & $\begin{array}{l}\text { 3.5-month-old, female } \\
\text { growing conventional pigs }\end{array}$ & $\begin{array}{l}\text { Gustatory stimulation with unknown odours } \\
\text { (citrus) at low or high (10x higher) } \\
\text { concentrations in pigs with or without } \\
\text { psychosocial stress (social isolation, } \\
\text { environmental impoverishment and stressful } \\
\text { visual and auditory stimuli) }\end{array}$ & fMRI/MRS (neuronal density) & $\begin{array}{l}\text { Citrus odours activated prepyriform, entorhinal, } \\
\text { orbitofrontal and anterior cingulate cortices, } \\
\text { dorsal striatum and hippocampus/increased } \\
\text { odour concentration induced higher brain } \\
\text { activity in the reward circuit/contrasted brain } \\
\text { responses in stressed } v \text {. non-stressed animals, } \\
\text { and notably decreased hippocampal activity } \\
\text { and neuronal density in stressed animals }\end{array}$ & $\begin{array}{l}\text { Coquery et al. (in revision)/ } \\
\text { Menneson et al. (in } \\
\text { revision) }\end{array}$ \\
\hline 17 & $\begin{array}{l}\text { Normal-weight and obese, } \\
\text { adult male and female } \\
\text { Yucatan minipigs (1 to } 2 \\
\text { years old) }\end{array}$ & $\begin{array}{l}\text { Gustatory stimulation with sucrose ( } 5 \% \text { or } \\
16 \% \text { ) in the same animals at three stages: } \\
\text { normal-weight, after } 3 \text { months of ad libitum } \\
\text { exposure to WD and } 3 \text { months after gastric } \\
\text { bypass or restrictive diet }\end{array}$ & 18FDG PET/fMRI & $\begin{array}{l}\text { Variations of brain activity were observed } \\
\text { depending on the weight/metabolic status of } \\
\text { the animals in the dorsal striatum, prefrontal } \\
\text { cortex and insular cortex }\end{array}$ & $\begin{array}{l}\text { Gautier Y., et al. } \\
\quad \text { (unpublished data) }\end{array}$ \\
\hline 18 & $\begin{array}{l}\text { Obese, } 2 \text {-year-old male and } \\
\text { female Yucatan minipigs }\end{array}$ & $\begin{array}{l}\text { Gustatory stimulation with sucrose ( } 5 \% \text { or } \\
16 \% \text { ) after overnight fasting in obese } \\
\text { minipigs } 3 \text { months after GB or restrictive diet } \\
\text { (sham, pair-feeding design) }\end{array}$ & fMRI & $\begin{array}{l}\text { Compared to sham, GB animals had higher } \\
\text { brain activity in orbitofrontal cortex, anterior } \\
\text { cingulate cortex, caudate nucleus and } \\
\text { hippocampus/compared to GB, sham animals } \\
\text { had higher brain activity in insular cortex, } \\
\text { somatosensory cortex and putamen }\end{array}$ & $\begin{array}{l}\text { Bergeat D./Coquery N., } \\
\text { et al. (unpublished data) }\end{array}$ \\
\hline
\end{tabular}


Val-Laillet

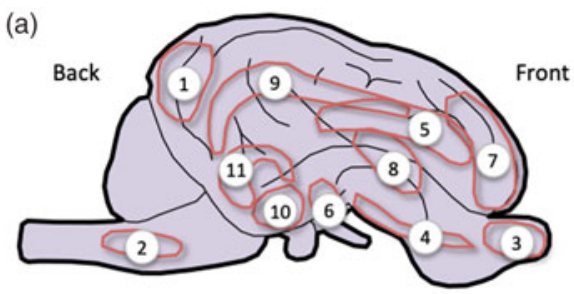

(b)

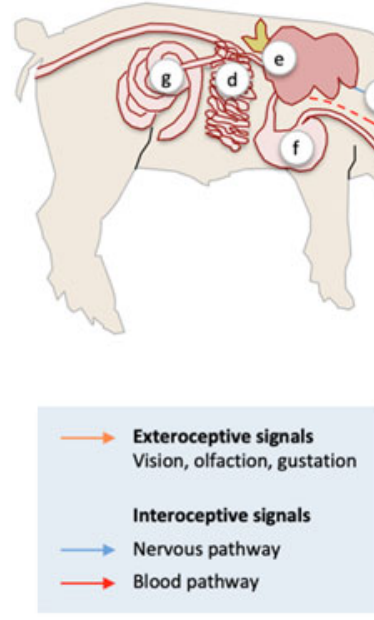

(c)

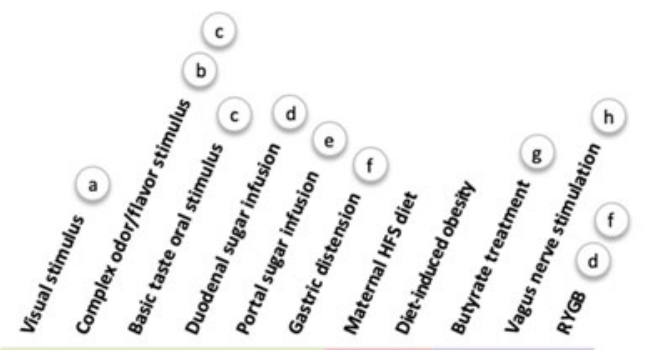

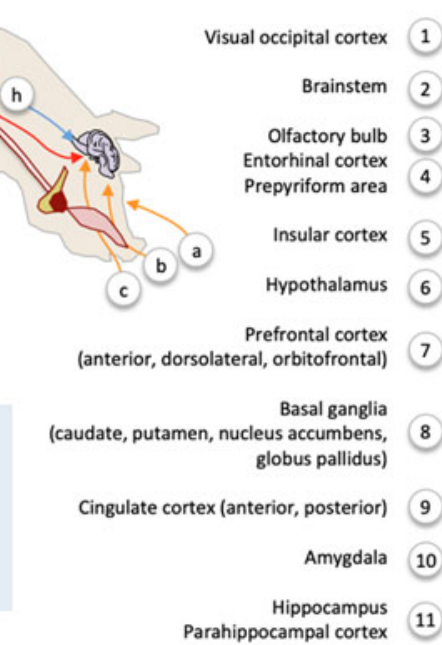

Figure 1 Meta-representation summarizing 10 years (2008 to 2018) of nutrition-related functional brain imaging data in the pig model. (a) Schematic representation of a pig's brain with the main ROI (1 to 11) explored during the studies described in Table 1. (b) Schematic representation of a pig with the gut-brain axis and different levels ( $a$ to $h$ ) of sensory/nutrient stimulation or treatment. (c) Synthetic table showing the brain ROls that were modulated by different types of sensory/nutrient stimulation (in green) or treatment (HFS diet in red, possible therapies in purple). For explanations, please refer to the reference numbers presented in Table 1. Visual stimulation: 15; complex odour/flavour stimulus: 3, 7, 10, 18; basic taste oral stimulus: 8 , 15, 16; duodenal sugar infusion: 6,8 portal sugar infusion: 6; gastric distension: 2; maternal HFS diet: 14; diet-induced obesity: 4, 5, 9, 16; butyrate treatment: 11; vagus nerve stimulation: 1, 12, 13; Roux-en-Y gastric bypass: 16, 17. An asterisk indicates a significant modulation of the brain ROI with the type of stimulation or treatment. Absence of an asterisk for a specific ROI and stimulation/treatment corresponds either to an absence of modulation or to missing data. The two sets of ROI represented by the frontostriatal network are highlighted (darkest blue) because these were almost systematically modulated in our studies and are part of the reward circuit described in rodents and humans. ROI = regions of interest; HFS = high-fat-sugar.

stimulations can be performed within the same imaging session, contrary to nuclear imaging (positron emission tomography (PET) and single-photon emission computed tomography (SPECT). The fMRI modality has already been implemented and used in the pig, notably to assess brain activity after deep-brain stimulation (Knight et al., 2013; Gibson et al., 2016), but to our knowledge, the work performed by Coquery et al. (2018) is the first to describe BOLD brain responses to visual (Figure 1a) and food stimuli in the pig. We showed that quinine and sucrose stimulations (Figure 1c) induced different brain activation patterns in gustatory, hedonic and cognitive areas (Table 1; Coquery et al., 2018). This might contribute to the understanding of the effects of bitter compounds on gut physiology and behaviour, for which significant effects were observed on gastric emptying, intestinal motility, gastrointestinal hormones and food intake (Fu et al., 2016; Roura et al., 2016).

\section{Brain responses to preferred or aversive food flavours}

Previous review papers explained why and how pig models could help disentangle the complex processes underlying food perception and preferences, and how such studies might benefit biomedical research (Clouard et al., 2012c; Roura et al., 2016). From 2011, we published the first studies using functional imaging to describe brain responses to conditioned food preferences and aversions in pigs, using 99mTc-HMPAO SPECT (Gaultier et al., 2011; Boubaker et al., 2012; Clouard et al., 2014) and 18F-FDG PET (Clouard et al., 2012a) to map cerebral blood flow and brain glucose metabolism, respectively. We validated the use of brain imaging in anaesthetized pigs and confirmed that the brain is still able to integrate and react to food sensory stimuli (e.g. flavours) according to individual positive or negative experience and associated internal states (Table 1; Gaultier et al., 2011 and 2012c). Different brain responses were identified in a neural network including frontostriatal and limbic areas, which are known to be involved in the regulation of food intake and pleasure in the human and rodents (Figure $1 \mathrm{~b}$ and $\mathrm{c}$ ). Associative conditioning between post-ingestive consequences and the meal's flavours shaped further hedonic valuation and food choices, which highlighted the gut-brain mechanisms influencing eating behaviour in pigs. This model might be useful to investigate the onset of food aversion consequent to invasive medical treatments, such as radiotherapy or chemotherapy, or exacerbated food 
preferences mediated by hedonic reinforcers such as added sugar (Clouard et al., 2012c).

\section{Impact of the metabolic or emotional status on brain responses to food signals}

Brain responses to food stimuli can be modulated by previous associative conditioning but also by the individual's metabolic or psychological state. In rodents, it has been shown that taste/olfactory perception capacity decreased with visceral fat increase (Fernandez-Garcia et al., 2017), and Thanos et al. (2008) documented significant changes in brain glucose metabolism in obese compared to lean rats exposed to appetitive food scent. Even though this question was not investigated in the pig model, we explored another relationship between the internal state and brain responses to odours. Emotional and physiological responses to stress are known to impact olfactory perception (Hoenen et al., 2017). We recently aimed to describe the consequences of a psychosocial stress in pigs on the gut-brain axis, behaviour and brain responses to olfactory food stimuli. We exposed stressed and control animals to low/high concentrations of novel food odours (Figure 1b) and showed activations in the prepyriform, entorhinal, orbitofrontal, and anterior cingulate cortices, dorsal striatum and hippocampus. We also showed that high-concentration olfactory stimuli induced a higher brain activity (Table 1; Coquery et al., in press). More interestingly, pigs with a psychosocial stress had lower brain responses in the right hippocampus compared to unstressed control pigs, as well as lower magnetic resonance spectroscopy-estimated neuronal density in the hippocampus, which suggested an impact of the internal state on cognitive and limbic processes at the brain level (Table 1; Menneson et al., 2019).

\section{Impact of weight gain and obesity on brain functions}

\section{Brain anomalies in diet-induced obese minipigs}

The use of preclinical models is very important in deciphering the determinants of obesity, eating disorders and metabolic diseases, but also to identify novel predictive biomarkers and innovative therapeutic strategies focused on the gut-brain axis (Val-Laillet et al., 2015; Obrenovich et al., 2016). The limited size of minipigs enables longitudinal studies at the adult age using the same imaging machines as in humans. The first studies using the minipig as a model of obesity date back to the 1980s (e.g. Phillips et al., 1982), but most of the publications appeared after 2000 (Johansen et al., 2001; Larsen et al., 2005; Christoffersen et al., 2007; Lee et al., 2009; Madsen et al., 2010; Val-Laillet et al., 2010c). Brain activity was described for the first time in obese minipigs in the Göttingen breed (Val-Laillet et al., 2011a), and then in the Yucatan (Ochoa et al., 2016a). Brain functional characteristics or anomalies associated with obesity and weight gain have been well described in the humans, encompassing initial high sensibility to highly palatable food stimuli in highrisk individuals (i.e. reward surfeit), but also decreased brain responses in the prefrontal cortex and striatum in obese patients (i.e. reward deficit), as well as a blunted dopaminergic system (Burger and Stice, 2011; Blum et al., 2015).

Even though evidence suggests that chronic exposure to energy-dense palatable foods provokes a switch in the hedonic and motivational brain processes (Burger and Stice, 2011), and that successful BW loss can reverse some obesity-related brain anomalies (Le et al., 2007), there was no clear demonstration showing that these brain anomalies are induced by (or concomitant to) weight gain in obese people and not pre-existent to it. Our brain imaging study in the minipig (Table 1; Val-Laillet et al., 2011a), in association with physiological data (Val-Laillet et al., 2010b and 2010c), was the first to demonstrate that diet-induced obesity could induce brain anomalies in comparison to lean subjects, including decreased basal metabolism in the prefrontal cortex and reward circuit (Figure 1; diet-induced obesity). These results suggest that some characteristics of the reward-deficit phenotype observed in obese humans were probably an acquired feature of obesity, induced by regular excess food intake.

\section{Impact of specific nutrients on brain anomalies in obese minipigs}

Following the 2011 demonstration in obese minipigs, two questions arose: Are weight gain and excess calorie intake only liable for these brain anomalies described in obese subjects? And does food quality, independently from the quantity consumed, have a role in shaping brain activity in obese subjects? In two additional independent studies in obese minipigs, we decided to compare different isocaloric obesogenic diets differing in terms of lipid or carbohydrate quality, respectively. The first study compared a 5-week exposure to three obesogenic diets only differing in the nature of lipids used for their composition (i.e. fish oil/n-3, sunflower oil/n-6, or lard/saturated fatty acids). n-3 fatty acids inhibit the production of proinflammatory cytokines (Parker et al., 2006), and n-3 supplementation (docosahexaenoic acid (DHA)) can increase the activity of the prefrontal cortex (McNamara et al., 2010), which is one of the brain areas found to be deactivated in obese humans and minipigs (Le et al., 2006; Volkow et al., 2009; Val-Laillet et al., 2011a). We hypothesized that $n-3$ might prevent the onset of central inflammation and protect brain areas involved in food intake control. We demonstrated significant changes in terms of blood-brain barrier (BBB) permeability and basal brain glucose metabolism according to the diets (Table 1; Val-Laillet et al., 2011b and 2013). Contrary to what was expected, we showed that a diet (overly) enriched with $n-3$ protected neither the BBB nor the basal metabolism of brain areas that are dysfunctioning in the context of obesity (Figure 1; diet-induced obesity). Consistent results were obtained on intestinal permeability (Lalles et al., 2011 and 2013), suggesting global effects of the diets on the gut-brain axis. Excessive dietary $n-3$ might increase the fluidity of intestinal and BBB cell membranes, thereby increasing their permeability and facilitating the invasion of proinflammatory 
compounds towards blood and the brain. Even though this hypothesis still needs validation, these results highlight the need for precise recommendations in terms of dietary $n-3$, because excessive supplementation might be as deleterious as a deficiency for the gut and brain functions. The European Food Safety Authority (EFSA) stated that dietary recommendations for eicosapentaenoic acid and DHA for European adults are between 250 and $500 \mathrm{mg} / \mathrm{day}$, and that supplemental intakes at doses up to $5 \mathrm{~g} /$ day do not raise safety concerns for adults in terms of cardiovascular disease risk, glucose homeostasis or immune function (European Food Safety Authority, 2012). n-3 supplementation in our minipig study was $1.9 \mathrm{~g} /$ day in average, which corresponded to $3.2 \mathrm{~g}$ of $\mathrm{n}-3$ per day in a normal-weight $(63 \mathrm{~kg})$ adult woman. This was above the recommended dose and below the tolerable upper intake level of $n-3$ according to the EFSA, but no other study in our knowledge ever investigated brain metabolism outcomes at these doses.

The second study relating nutrient quality and brain activity compared a long-term exposure to three obesogenic isocaloric diets, only differing in the nature of their carbohydrates (i.e. starch as control, compared to glucose and fructose) (Ochoa et al., 2014, 2016a and 2016b). Fructose, which is overly used in industrial food products, has been incriminated for its role in the onset of metabolic syndrome and its impact on gut-brain metabolic signals in rodents (Dornas et al., 2015; Ochoa et al., 2015; Legeza et al., 2017), but counterarguments have been raised (Rizkalla, 2010), and the results obtained in the minipig model feed the controversy. Obesogenic diets altered fat accretion and metabolic profiles independently of dietary carbohydrates, but only pigs chronically fed the fructose diet developed a strong preference for it (Ochoa et al., 2014 and 2016b). After 7 months of diet, all groups presented a similar weight gain and insulin sensitivity index; and compared to starch, chronic exposure to fructose and glucose induced bilateral activations in several reward-related brain regions, including prefrontal and striatal areas (Figure 1; diet-induced obesity), with no significant differences between fructose and glucose groups (Table 1; Ochoa et al., 2016a). Consistent with the dynamic vulnerability model (Stice et al., 2013), it is plausible that our minipigs did not develop a blunted reward response yet, since they were food-restricted for the entire experimental diet exposure and became only moderately obese. Brain metabolism differences observed here would rather be in favour of the reward surfeit theory and hypersensitization of the reward circuit, which might precede the reward deficit status, which was previously validated in a massively obese minipig model (Val-Laillet et al., 2011a).

\section{Dynamic relationship between brain activity, body weight and diet changes}

Among the hot questions on the relationship between excessive consumption of palatable foods and the emergence of brain dysfunctions is the onset dynamic of these anomalies and its relationship with BW status. It is still unknown whether regular consumption of highly palatable foods without weight gain, or different strategies to lose weight, can also influence neural networks and related behavioural functions. Gautier Y., et al. (unpublished data) aimed at following the neurocognitive processes in a cohort of adult minipigs, from a normal-weight status when exposed daily to a high-fat-sugar (HFS) diet rationed not to exceed the metabolic needs, to the onset of obesity when ad libitum food intake was permitted, and finally to a third stage when animals were subjected either to a restrictive diet or bariatric surgery to make them lose weight. This is the first study describing longitudinally the impact of diet switch and/or BW variations on metabolic and neurocognitive processes, using two in vivo brain imaging modalities (PET and FMRI) in the same minipigs. Our preliminary and yet unpublished data indicated that brain responses to sucrose were dependent on both the metabolic/nutritional status and BW, and that significant variations of brain activity were detected in the dorsal striatum, prefrontal cortex and insular cortex. Complete results are still pending, but we hope to identify brain imaging markers that might predict weight gain or weight loss after nutritional interventions, in combination with metabolic markers (e.g. hormonal, transcriptomics, metabolomics and metagenomics) to hypothesize the potential underlying microbiota-gut-brain mechanisms influencing eating behaviour and disorders.

\section{Perinatal nutrition and the gut-brain axis development}

Developmental origins of health and diseases

The concept of developmental origins of health and diseases, initially described by David Barker (Barker, 2001), postulates that early nutritional environment can modify the progeny's metabolism, physiology and behaviour, and influence its susceptibility to declare further pathologies. In humans, it is admitted that maternal obesity increases the prevalence of obesity and metabolic syndrome in the progeny (McGuire et al., 2010). The effects of high-calorie and high-lipid diets on glucose metabolism, energy balance, cardiovascular function and adiposity of the progeny have been demonstrated in rodents, pigs and non-human primates (Albuquerque et al., 2006; Williams et al., 2014; Wang et al., 2016), similarly to the susceptibility to declare cognitive, emotional, psychiatric and behavioural disorders (Bale et al., 2010). Maternal obesity and/or a plethoric HFD during gestation and lactation also induce brain anomalies, with the possible onset of neuroinflammation, decreased spatial memory, neurogenesis and brain plasticity alterations (e.g. in the hippocampus and reward circuit). The microbiota represents a major actor of the gut-brain communication (Bienenstock et al., 2015; Carabotti et al., 2015). In mice, maternal consumption of a HFD during gestation and lactation impacts intestinal immunity and microbiota of the progeny (Myles et al., 2013), and a direct 
relationship exists between excessive food intake before weaning, microbiota composition and body adiposity accretion (Sefcikova et al., 2011).

\section{Early nutritional programming of neurocognitive functions in the minipig}

The pig provides a great opportunity to investigate the consequences of nutritional programming for the gastrointestinal tract (Guilloteau et al., 2010) and neurodevelopment (Mudd and Dilger, 2017). Recent studies focused on the impact of perinatal nutrition on brain functions in pigs, showing, for instance, that perinatal choline deficiency and maternal dietary choline both influence brain development in young pigs (Mudd et al., 2016 and 2018). Most of the translational research on perinatal programming of obesity and associated diseases has been performed in rodent models, while the use of large animals such as pigs is scarce (Gonzalez-Bulnes and Chavatte-Palmer, 2017).

To fill this gap, we performed an experiment in the Yucatan minipig model and constituted two groups of sows fed either a standard or an HFS diet during the last third of gestation and all the lactation period. Maternal daily food rations were calculated to prevent obesity and BW differences between control and HFS groups (contrary to most studies in rodents). All the piglets from both groups were fed a standard diet after weaning. The HFS maternal diet increased plasma levels of triglycerides and free fatty acids in weaned piglets, but more interestingly, it significantly decreased the faecal amount of short-chain fatty acids (SCFA) 100 days after birth, even though all animals were fed a standard diet after weaning (Val-Laillet et al., 2017). This indicates a decreased fermentation activity of the intestinal microbiota, already detected in HFS sows. An alternative hypothesis would be an increased intestinal absorption/use of SCFAs, and further investigations in terms of intestinal metabolism or metagenomic sequencing are required to disentangle this question. In the holeboard test (spatial learning task), where the animals have to learn and remember the location of food rewards hidden in a complex environment, Yucatan piglets born from HFS sows had increased reference and working memory scores compared to control (Val-Laillet et al., 2017), which corroborated previous data in conventional piglets (Clouard et al., 2016). This might be explained by increased cognitive abilities and/or an increased motivation to perform/complete the cognitive task since it was reinforced by highly palatable food rewards (chocolate/sugar-coated peanuts). Any change in the motivation to obtain these food rewards can influence the animals' memory scores. This is where the exploration of brain functions and activity is fundamental to interpret such ambivalent results.

After post-weaning behavioural tests, some piglets were euthanized to explore their brain plasticity and neuroinflammation in the hippocampus and prefrontal cortex. The hippocampus is involved in spatial learning, while the prefrontal cortex has a major role in hedonic valuation of food and goal-oriented behaviour. Interestingly, the piglets born from
HFS mothers had a smaller hippocampal granular cell layer and a decreased neurogenesis (Val-Laillet et al., 2017). An increased microglial cell density was also observed in the prefrontal cortex, and the activation of microglia was increased in the hippocampus and prefrontal cortex (Val-Laillet D., Kanzari A. et al., unpublished data). These observations rather praise in favour of decreased cognitive abilities and a possible alteration of the prefrontal processes involved in food valuation and motivation, due to neuroinflammation processes.

\section{Long-term impact of early nutritional programming}

Some piglets were kept alive until the adult age to perform new behavioural tests, metabolic measures and brain exploration with in vivo imaging techniques. The differences observed in the young age for the holeboard test were not found again, but during the maze test (another spatial cognitive test that is not reinforced by food rewards, contrary to the holeboard test), minipigs born from HFS mothers presented more stress and reduced cognitive abilities (Table 1; Gautier et al., 2018). More interesting is the fact that these animals showed a reduced basal glucose metabolism in the prefrontal cortex and nucleus accumbens (Figure 1; maternal HFS diet), which are both parts of the brain reward circuit. We also demonstrated that these animals also presented a decreased dopamine and/or serotonin transporter availability in the striatum and hippocampus. These brain anomalies are usually observed in obese subjects, as previously demonstrated in humans (Wang et al., 2001; Le et al., 2006; Volkow et al., 2008 and 2009) and minipigs (Val-Laillet et al., 2011a; Ochoa et al., 2016a). It is consequently striking to find them in animals that were fed a standard diet from weaning without abnormal weight gain or metabolic disease until the adult age. This suggests that the HFS diet might program the brain even in the absence of weight problem and possibly modulate adaptation mechanisms to further dietary challenge. Further research is needed in this model to demonstrate that the brain and the digestive system, including gut microbiota, can influence each other with causal relationship to modulate the susceptibility to health and diseases, and notably behavioural and metabolic disorders.

\section{Impact of nutritional preventive or therapeutic strategies on brain activity}

As highlighted in the previous section, data are lacking to connect the microbiota and gut physiology to neurocognitive outcomes in the pig model. Through preventive or therapeutic interventional strategies aimed at influencing susceptibility to health and diseases, it is possible to modulate metabolism, brain and behaviour. In this last section, we will review three examples of interventions for which brain activity modulation was documented in the pig model. 
Impact of food functional ingredient/supplementation on brain activity

Because many evidences indicate a crucial role for the microbiota in regulating different aspects of behaviour and mental health, as well as comorbidities related to eating and metabolic disorders (van de Wouw et al., 2017), pre- and probiotics open the way to novel biotherapeutic strategies. Pinto-Sanchez et al. (2017) recently demonstrated that probiotic supplementation reduced depression scores and increased the quality of life in patients with inflammatory bowel disease. Interestingly, changes in brain activity via fMRI, with reduced reactivity of the limbic system, were also shown. Comparison data are lacking in the pig model, but the use of maternal prebiotics can impact the progeny's growth, intestinal microbiota, morphology and immunity in pigs (Le Bourgot et al., 2014, 2016, and 2017). The use of dietary prebiotics early in life in piglets also supported recognition memory and modulated the concentrations of SCFAs in the colon, blood and the brain, as well as hippocampal serotonin (Fleming et al., 2017). Interestingly, we recently showed that oral supplementation of butyrate might shape brain activity and plasticity (Val-Laillet et al., 2018). Butyrate is an SCFA that is naturally produced in the gut through bacterial fermentation of dietary fibres, playing an essential role in gastrointestinal functions (Guilloteau et al., 2010). This microbiota metabolite (i.e. postbiotic) has a trophic role for colonocytes, modulatory properties on gut morphology and functional plasticity, and is part of the histone deacetylase inhibitors having positive effects on long-term memory processes (Guilloteau et al., 2010; Val-Laillet et al., 2018). For that matter, some authors suggested that butyrate could prevent memory impairment and improve cognition through the upregulation of neurotrophic factors (Moretti et al., 2011; Valvassori et al., 2014). To tackle this question in the pig model, we compared two groups of juvenile animals that were exposed for 3 weeks to either oral sodium butyrate or control treatment (Table 1; Val-Laillet et al., 2018). We demonstrated that oral butyrate supplementation triggered basal brain glucose metabolism changes in the hippocampus and nucleus accumbens, which are involved in cognitive and hedonic processes (Figure 1g). Interestingly, post-mortem immunohistochemistry data revealed a higher granular cell layer volume, cell proliferation and neurogenesis with butyrate treatment, supporting a positive modulatory role of this postbiotic on hippocampal plasticity and neurocognitive processes (Val-Laillet et al., 2018).

Apart from pre-, pro- and postbiotics, other kinds of food functional ingredients can be used to modulate behaviour and brain activity. Stressful environments/events are known to alter well-being and eating behaviour, sometimes leading to appetite loss and anorexia or to food cravings and hyperphagia. This has been described in humans (Guarda et al., 2015; Geiker et al., 2018) as in pigs (Clouard et al., 2012c). In young pigs, we demonstrated positive effects of sensory feed functional ingredients based on natural plant extracts on eating behaviour, with increased feed preference and intake after a feed transition, for example (Clouard et al., 2012b; Clouard and Val-Laillet, 2014). Then, we explored brain responses to one of these feed functional ingredients and showed that the perception of the ingredient (Figure $1 \mathrm{~b}$ and $\mathrm{c}$ ) in familiarized individuals induced different responses in reward and perception brain areas compared to familiar control feed flavour in naive animals (Table 1; ValLaillet et al., 2016). In addition to its potential application in animal production to improve well-being and feed intake, translational applications might be assessed in fragile human populations suffering from appetite loss, decreased motivation to eat and/or denutrition. These food functional ingredients might also be tested in the context of degraded/ stressful environments to assess their ability to counterbalance the effects of stressors at the brain level.

Impact of chronic vagus nerve stimulation on brain activity Chronic vagus nerve stimulation (VNS) is used in clinical practice as a therapy for refractory epilepsy and some psychiatric disorders (Vonck et al., 2009), but it is also a promising potential strategy to fight against obesity and an original methodological approach to understand how the gut-brain signals transmitted via the vagus nerve can modulate brain activity, metabolism and eating behaviour. The pig model was rapidly in good position among candidate animal models to assess VNS against obesity (for review see Val-Laillet et al., 2010a). The vagus nerves convey much information emanating from the gut, notably information related to gastric distension, one of the first satiation signals. We showed in young pigs that the activity of several brain areas was found to be significantly associated with an increase in gastric distension pressure (Figure $1 \mathrm{f}$ ), such as the olfactory bulb, prefrontal cortex and amygdala (Layec et al., 2009; Sauleau et al., 2009). But after bilateral vagotomy, only a limited number of brain areas still responded to gastric pressure (Table 1; Sauleau et al., 2009). A pilot study also demonstrated that chronic gastric distension (via a gastric balloon; Figure 1f) activated the nucleus accumbens (Layec et al., 2009). With VNS, the aim is to mimic the nervous gut-brain signals emitted with stomach distension. The first pilot study investigating brain responses to VNS was performed in lean juvenile pigs (Table 1; Biraben et al., 2008). At that time, nuclear functional brain imaging in the pig model was emerging, and our digital pig brain atlas (Saikali et al., 2010) was not available, which explains why the identification of activated brain structures was tricky and the interpretation very limited. Two years later, we reiterated a similar experiment in obese adult minipigs and demonstrated that chronic VNS during 14 weeks decreased feed intake, prevented the animals from gaining further BW contrary to sham animals, and modified the feed preferences with a decreased consumption of high-sucrose feed and increased consumption of standard feed (Val-Laillet et al., 2010a).

With time, both VNS and brain imaging procedures were improved in the pig model, and two new studies were published (Malbert et al., 2017b and 2017a). A first experiment compared three chronic VNS patterns in growing pigs (S1, S2 and S3; Table 1). Only S2 and S3 activated the dorsal vagal 
complex and had an impact on the prefrontal cortex, contrary to S1 (Table 1; Malbert et al., 2017a; Figure 1h). Only S2 and S3 significantly reduced daily ingestion, the duration of eating bouts during the meal, as well as the consumption of the high-lipid diet during the three-choice feed test, where the animals had simultaneous access to control, high-lipid and high-glucose feeds provided by a three-trough robotic feeder (Malbert et al., 2017a). Taken together, these results demonstrate how specific nervous signals emanating from the gut can modulate the activity of the brain network involved in food intake regulation and goal-oriented behaviour. This also highlights the importance of the prefrontal cortex in modulating food motivation and preferences. Another study in obese minipigs reused the same VNS procedure as that previously successfully tested (Val-Laillet et al., 2010a) to investigate the VNS impact on metabolism and brain activity (Table 1; Malbert et al., 2017b). Mean whole-body insulin sensitivity and hepatic glucose uptake rate were significantly lower in non-stimulated obese minipigs compared to lean minipigs, and contrary to stimulated obese minipigs. Stimulated animals also had increased glucose metabolism in the anterior prefrontal cortex and cingulate cortex compared to non-stimulated animals (Table 1; Malbert et al., 2017b; Figure 1h). Once again, this study demonstrated that chronically mimicking satiation signals emanating from the gut could improve the activity of the prefrontal cortex, which is known to have inhibitory inputs towards the orexigenic brain areas and to be deactivated in obese individuals.

\section{Impact of bariatric surgery on brain activity}

To conclude this section on interventional strategies, it is interesting to evoke what is still one of the most effective therapeutic compromises against morbid obesity: the Roux-en-Y gastric bypass (RYGB; Kang and Le, 2017). A recent paper reviewed the evidences derived from neuroimaging and animal (mainly rodent) studies (Hankir et al., 2018), explaining how a metabolic surgical procedure such as the RYGB, which is drastically reorganizing gut, including peptide hormones and microbiota metabolites, is also reshaping homeostatic and hedonic brain processes. Different animal models of bariatric surgery have been described (Rao et al., 2010), and the first demonstrations of RYGB in the pig model, to our knowledge, date back to the 1990s (Frantzides et al., 1995; Potvin et al., 1997). Since then, the pig and minipig models have been widely used to describe the functional mechanisms of RYGB. Not being exhaustive, we can refer to studies having investigated gastrointestinal histological morphology (Gentileschi et al., 2006), long-term weight loss in superobese minipigs (Birck et al., 2013), changes in adipose tissue distribution (Chavez-Talavera et al., 2017), $\beta$-cell function, biliary function and glucose metabolism (Lindqvist et al., 2014; Sham et al., 2014; Baud et al., 2016; Chavez-Talavera et al., 2017; Lindqvist et al., 2017a), as well as incretins regulation (Lindqvist et al., 2017b), for example. Despite all of this work, we found no study on the consequence of RYGB (or any other bariatric surgery) on brain activity and metabolism in pigs.
Identifying a way to reproduce the gut-brain effects of RYGB without a real surgery per se would free the patients from possible deleterious consequences of invasive bariatric surgery (Lupoli et al., 2017). That is why preclinical research in a relevant model, such as the pig, is necessary. In a longitudinal study (Gautier Y., Bergeat D., et al., unpublished data), we aimed at phenotyping diet-induced obese Yucatan minipigs subjected either to the RYGB (cf. Baud et al., 2016 for surgery procedure) or a pair-fed restrictive dietary treatment. Peptide and hormone measurements, gastrointestinal histological morphology and immunohistochemistry, transcriptomic, metabolomic and metagenomic analyses were performed to provide a systemic description of the intestinal (including microbiota) and metabolic phenotype. The obese minipigs were also subjected to fMRI and PET brain imaging before and 3 months after the surgery (RYGB or sham) to investigate brain responses to sucrose (Figure 1d and f). Our preliminary results (Table 1; Bergeat D., et al., unpublished data) are in line with human brain imaging studies showing a modulation of the mesolimbic and frontostriatal pathway after RYGB (Ochner et al., 2011; Scholtz et al., 2014). To date, the minipig is the only preclinical model for which such an analogy has been described, which opens the way to further interventional studies aiming at unravelling the complex gut-brain interactions shaping eating behaviour after bariatric surgery.

\section{Critical conclusion}

This overview of 10 years of nutrition research using in vivo brain imaging in the pig illustrates how relevant this preclinical model is to disentangle the respective roles of food, gut-brain signals and metabolic status in modulating brain activity and eating behaviour. The research topics exposed in this review cover the fields of food technology, digestive physiology, sensory sciences, metabolic adaptation, nutritional programming, experimental surgery and behavioural neurosciences. Despite the intricacy of all sensory, physiological and metabolic signals susceptible to modulating brain activity, several interventional targets were identified in these studies. Most of this work remains rather descriptive and only superficially brushes mechanistic hypotheses. In the future, more applied and preclinical research investigating concrete strategies to improve health and well-being, both in animals and humans, are needed. Identifying brain activity and metabolism changes is a prerequisite to validate the existence of gut-brain processes that can be used as operational leverages. But the finality is clearly to operate actions: to identify at-risk metabolic and neurocognitive phenotypes, to improve individual adaptation abilities towards challenging diets or environments, to change individual eating habits in favour of healthy behaviours.

Coming back to the pig model, it is important to evoke its limitations/advantages and the questions arising from ethical concerns. Both these considerations should help identify the added value of animal experimentation and provide a 
rationale for its reasonable use when no alternative exists, and as long as none has emerged. In terms of limitations of the pig model, the main constraints lie in the fact that all brain imaging studies presented here were performed in anaesthetized animals, which moderates the analogy with human neurobehavioral studies in the same thematic. In spite of that, we identified, on a recurring basis, some brain activity in highly integrative neural networks that are characteristic of complex cognitive processes. Of course, brain activity during general anaesthesia is weakened and different from that in the awakened state, but all these studies demonstrated that the anaesthetized brain can still integrate and interpret positive or negative food stimuli in relation to the internal state and individual experience. This opens a small window on what might happen also in the awakened animals.

Although the pig is a very good model for nutritional and cognitive studies, there are dimensions of eating behaviour that cannot be modelled with it, such as psychological and cultural influences. For example, even if a pig model of anorexia nervosa can mimic metabolic and behavioural symptoms, it has nothing to do with the real disease (Danek et al., 2017). Similarly, an individual history leading someone to become obese or food-addict cannot be strictly reproduced in the animal. Emotional, motivational and hedonic dimensions of eating can be investigated in pigs, but factors influencing these in the human are much more complex than in pigs. Cognitive control of eating is a very important leverage to change individual habits (Val-Laillet et al., 2015), but it is specific to humans and does not apply to animals. What justifies the use of the pig model though is the opportunity to investigate questions that cannot be solved by human studies only, as well as to control specific experimental conditions in order to disentangle the respective roles of many biological factors and influences. Animal studies are still legally mandatory before testing new medicines or medical treatments in the human. A precise control of the environment and diet is possible in animal models and completely illusionary in humans. Induction of a disease or disorder, or long-term interventions with possible deleterious consequences in terms of health and well-being, cannot be justified in the human and is still tolerated in animals, when there is a clear rationale and strict ethical conduct. All these arguments praise in favour of a translational research combining studies in relevant animal models such as the pig, as well as studies in the human, with a constant and bilateral dialog between them, to achieve better public health outcomes.

\section{Acknowledgements}

The author would like to acknowledge the scientific committee of the 14th International Symposium of Digestive Physiology of Pigs, and especially Eugeni Roura, for having invited him to write this review and present his work at the conference. The author also insists on the fact that all the research advances presented in this review are the result of a collective work and therefore acknowledges all the persons involved. The complete financial disclosure is provided in the Supplementary Material S1.

(1) D. Val-Laillet 0000-0002-6256-7737

\section{Declaration of interest}

The author declares no conflict of interest.

\section{Ethics statement}

The experiments performed by our group and presented in this review paper were conducted in accordance with the current ethical standards of the European Community (Directive 2010/63/EU; Agreement No. A35-622) for experimental facilities, and Authorization No. 35-88 or 01894 to experiment on live animals for the principal investigators of the studies. The Regional Ethics Committee for Animal Experimentation of Brittany and French Ministry of Research have validated and authorized the entire procedures described in these studies. Specific authorization numbers are mentioned in the original papers.

\section{Software and data repository resources}

Most of the data presented in this review paper were not deposited in an official repository, except brain imaging data from two articles, which are available from the DRYAD public repository (http://datadryad.org/). For Val-Laillet et al. (2016), please refer to doi:10.5061/dryad.ck3g3. For Ochoa et al. (2016a), please refer to doi:10.5061/dryad.ch4nr.

\section{Supplementary material}

To view supplementary material for this article, please visit https://doi.org/10.1017/S1751731119001745

\section{References}

Albuquerque $\mathrm{KT}$, Sardinha $\mathrm{FL}$, Telles MM, Watanabe RL, Nascimento $\mathrm{CM}$, Tavares do Carmo MG and Ribeiro EB 2006. Intake of trans fatty acid-rich hydrogenated fat during pregnancy and lactation inhibits the hypophagic effect of central insulin in the adult offspring. Nutrition 22, 820-829.

Bale TL, Baram TZ, Brown AS, Goldstein JM, Insel TR, McCarthy MM, Nemeroff CB, Reyes TM, Simerly RB, Susser ES and Nestler EJ 2010. Early life programming and neurodevelopmental disorders. Biological Psychiatry 68, 314-319.

Barker DJ 2001. The malnourished baby and infant. British Medical Bulletin 60 69-88.

Baud G, Daoudi M, Hubert T, Raverdy V, Pigeyre M, Hervieux E, Devienne $M$, Ghunaim M, Bonner C, Quenon A, Pigny P, Klein A, Kerr-Conte J, Gmyr V Caiazzo $R$ and Pattou $F$ 2016. Bile Diversion in Roux-en-Y gastric bypass modulates sodium-dependent glucose intestinal uptake. Cell Metabolism 23, 547-553.

Bienenstock J, Kunze W and Forsythe P 2015. Microbiota and the gut-brain axis. Nutrition Reviews 73 (suppl. 1), 28-31.

Biraben A, Guérin S, Bobillier E, Val-Laillet D and Malbert CH 2008. Central activation after chronic vagus nerve stimulation in pigs: contribution of functional imaging. Bulletin de l'Académie Vétérinaire de France 161, 441-448.

Birck MM, Vegge A, Stockel M, Gogenur I, Thymann T, Hammelev KP, Sangild PT, Hansen AK, Raun K, von Voss P and Eriksen T 2013. Laparoscopic Roux-en-Y gastric bypass in super obese Gottingen minipigs. American Journal of Translational Research 5, 643-653.

Blum K, Thanos PK, Oscar-Berman M, Febo M, Baron D, Badgaiyan RD, Gardner E, Demetrovics Z, Fahlke C, Haberstick BC, Dushaj K and Gold MS 2015. Dopamine in 
the brain: hypothesizing surfeit or deficit links to reward and addiction. Journal of Reward Deficiency Syndrome and Addiction Science 1, 95-104.

Boubaker J, Val-Laillet D, Guerin S and Malbert CH 2012. Brain processing of duodenal and portal glucose sensing. Journal of Neuroendocrinology 24, 1096-1105.

Burger KS and Stice E 2011. Variability in reward responsivity and obesity: evidence from brain imaging studies. Current Drug Abuse Reviews 4, 182-189.

Carabotti M, Scirocco A, Maselli MA and Severi C 2015. The gut-brain axis: interactions between enteric microbiota, central and enteric nervous systems. Annals of Gastroenterology 28, 203-209.

Chavez-Talavera O, Baud G, Spinelli V, Daoudi M, Kouach M, Goossens JF, Vallez E, Caiazzo R, Ghunaim M, Hubert T, Lestavel S, Tailleux A, Staels B and Pattou F 2017. Roux-en-Y gastric bypass increases systemic but not portal bile acid concentrations by decreasing hepatic bile acid uptake in minipigs. International Journal of Obesity (London) 41, 664-668.

Christoffersen BO, Grand N, Golozoubova V, Svendsen 0 and Raun K 2007. Gender-associated differences in metabolic syndrome-related parameters in Gottingen minipigs. Comparative Medicine 57, 493-504.

Clouard C, Jouhanneau M, Meunier-Salaun MC, Malbert CH and Val-Laillet D 2012a. Exposures to conditioned flavours with different hedonic values induce contrasted behavioural and brain responses in pigs. PLoS ONE 7, e37968.

Clouard C, Kemp B, Val-Laillet D, Gerrits WJ, Bartels AC and Bolhuis JE 2016. Prenatal, but not early postnatal, exposure to a Western diet improves spatial memory of pigs later in life and is paired with changes in maternal prepartum blood lipid levels. The FASEB Journal 30, 2466-2475.

Clouard C, Meunier-Salaun MC, Meurice P, Malbert CH and Val-Laillet D 2014. Combined compared to dissociated oral and intestinal sucrose stimuli induce different brain hedonic processes. Frontiers in Psychology 5, 861.

Clouard C, Meunier-Salaün MC and Val-Laillet D 2012b. The effects of sensory functional ingredients on food preferences, intake and weight gain in juvenile pigs. Applied Animal Behaviour Science 138, 36-46.

Clouard C, Meunier-Salaun MC and Val-Laillet D 2012c. Food preferences and aversions in human health and nutrition: how can pigs help the biomedical research? Animal 6, 118-136.

Clouard C and Val-Laillet D 2014. Impact of sensory feed additives on feed intake, feed preferences, and growth of female piglets during the early postweaning period. Journal of Animal Science 92, 2133-2140.

Coquery N, Menneson S, Meurice $P$, Janvier R, Etienne $P$, Noirot $V$ and Val-Laillet $D$ in press. fMRI-based brain responses to olfactory stimulation with two food additives at two different concentrations in the pig model. Journal of Food Science.

Coquery N, Meurice P, Janvier R, Bobillier E, Quellec S, Saint Jalmes H, Fu M, Roura $E$ and Val-Laillet D 2018. fMRI-based brain responses to quinine and sucrose gustatory stimulation for nutrition research in the minipig model: a proof-of-concept study. Frontiers in Behavioral Neuroscience 12, 151.

Danek M, Danek J and Araszkiewicz A 2017. Large animals as potential models of human mental and behavioral disorders. Psychiatria Polska 51, 1009-1027.

Dilger RN and Johnson RW 2010. Behavioral assessment of cognitive function using a translational neonatal piglet model. Brain, Behavior, and Immunity 24, 1156-1165.

Dornas WC, de Lima WG, Pedrosa ML and Silva ME 2015. Health implications of high-fructose intake and current research. Advances in Nutrition 6, 729-737.

European Food Safety Authority (EFSA) 2012. Scientific opinion on the tolerable upper intake level of eicosapentaenoic acid (EPA), docosahexaenoic acid (DHA) and docosapentaenoic acid (DPA). EFSA Journal 10, 2815.

Fernandez-Garcia JC, Alcaide J, Santiago-Fernandez C, Roca-Rodriguez MM, Aguera Z, Banos R, Botella C, de la Torre R, Fernandez-Real JM, Fruhbeck G Gomez-Ambrosi J, Jimenez-Murcia S, Menchon JM, Casanueva FF, FernandezAranda F, Tinahones FJ and Garrido-Sanchez L 2017. An increase in viscera fat is associated with a decrease in the taste and olfactory capacity. PLoS ONE 12, e0171204.

Fleming SA, Monaikul S, Patsavas AJ, Waworuntu RV, Berg BM and Dilger RN 2017. Dietary polydextrose and galactooligosaccharide increase exploratory behavior, improve recognition memory, and alter neurochemistry in the young pig. Nutritional Neuroscience 22, 499-512.

Frantzides CT, Carlson MA and Schulte WJ 1995. Laparoscopic gastric bypass in a porcine model. Journal of Laparoendoscopic \& Advanced Surgical Techniques $5,97-100$.
Fu M, Manchadi ML, De Jager N, Val-Laillet D, Guerin S and Roura E 2016. Bitter compounds delayed gastric emptying and induced intestinal smooth muscle relaxation in a pig model. In Chemical Senses 41, 17th International Symposium on Olfaction and Taste (ISOT), Yokohama, Japan.

Gaultier A, Meunier-Salaun MC, Malbert CH and Val-Laillet D 2011. Flavour exposures after conditioned aversion or preference trigger different brain processes in anaesthetised pigs. European Journal of Neuroscience 34, 1500-1511.

Gautier Y, Luneau I, Coquery N, Meurice P, Malbert CH, Guerin S, Kemp B, Bolhuis JE, Clouard C, Le Huerou-Luron I, Blat S and Val-Laillet D 2018. A maternal Western diet during gestation and lactation modifies adult offspring's cognitive and hedonic brain processes, behavior and metabolism in Yucatan minipigs. The FASEB Journal Jun 13:fj201701541. doi: 10.1096/fj.201701541

Geiker NRW, Astrup A, Hjorth MF, Sjodin A, Pijls L and Markus CR 2018. Does stress influence sleep patterns, food intake, weight gain, abdominal obesity and weight loss interventions and vice versa? Obesity Reviews 19, 81-97.

Gentileschi P, Gagner M, Milone L, Kini S and Fukuyama S 2006. Histologic studies of the bypassed stomach after Roux-en-Y gastric bypass in a porcine model. Obesity Surgery 16, 886-890.

Gibson WS, Ross EK, Han SR, Van Gompel JJ, Min HK and Lee KH 2016. Anterior thalamic deep brain stimulation: functional activation patterns in a large animal model. Brain Stimulation 9, 770-773.

Gieling ET, Schuurman T, Nordquist RE and van der Staay FJ 2011. The pig as a model animal for studying cognition and neurobehavioral disorders. Current Topics in Behavioral Neurosciences 7, 359-383.

Gonzalez-Bulnes A and Chavatte-Palmer P 2017. Contribution of large animals to translational research on prenatal programming of obesity and associated diseases. Current Pharmaceutical Biotechnology 18, 541-551.

Guarda AS, Schreyer CC, Boersma GJ, Tamashiro KL and Moran TH 2015. Anorexia nervosa as a motivated behavior: relevance of anxiety, stress, fear and learning. Physiology \& Behavior 152, 466-472.

Guilloteau P, Zabielski R, Hammon HM and Metges CC 2010. Nutritional programming of gastrointestinal tract development. Is the pig a good model for man? Nutrition Research Reviews 23, 4-22.

Hankir MK, Seyfried F, Miras AD and Cowley MA 2018. Brain feeding circuits after Roux-en-Y gastric bypass. Trends in Endocrinology \& Metabolism 29, 218-237.

Hoenen M, Wolf OT and Pause BM 2017. The impact of stress on odor perception. Perception 46, 366-376.

Johansen T, Hansen HS, Richelsen B and Malmlof R 2001. The obese Gottingen minipig as a model of the metabolic syndrome: dietary effects on obesity, insulin sensitivity, and growth hormone profile. Comparative Medicine 51, 150-155.

Kang JH and Le QA 2017. Effectiveness of bariatric surgical procedures: a systematic review and network meta-analysis of randomized controlled trials. Medicine (Baltimore) 96, e8632.

Knight EJ, Min HK, Hwang SC, Marsh MP, Paek S, Kim I, Felmlee JP, Abulseoud OA, Bennet KE, Frye MA and Lee KH 2013. Nucleus accumbens deep brain stimulation results in insula and prefrontal activation: a large animal FMRI study. PLoS ONE 8, e56640.

Lalles JP, Perrier C, Val-Laillet D and Malbert CH 2011. Alterations in ileal and colonic permeability by chronic intake of high-lipid diets enriched with omega 3 , omega 6 or saturated fat. Proceedings of the Nutrition Society 144, S836-S836.

Lalles JP, Perrier C, Val-Laillet D and Malbert CH 2013. Alterations in ileal and colonic permeability by chronic intake of high-lipid diets enriched with omega 3, omega 6 or saturated fat. Gastroenterology 144, S836-\$836.

Larsen MO, Juhl CB, Porksen N, Gotfredsen CF, Carr RD, Ribel U, Wilken M and Rolin B 2005. Beta-cell function and islet morphology in normal, obese, and obese beta-cell mass-reduced Gottingen minipigs. American Journal of Physiology-Endocrinology and Metabolism 288, E412-E421.

Layec S, Lapouble E, Val-Laillet D, Guerin S, Chauvin A, Heresbach D and Malbert $\mathrm{CH}$ 2009. Chronic but not accute gastric distension activates brain reward circuit. Gastroenterology 136, A583-A584.

Le DS, Pannacciulli N, Chen K, Del Parigi A, Salbe AD, Reiman EM and Krakoff J 2006. Less activation of the left dorsolateral prefrontal cortex in response to a meal: a feature of obesity. The American Journal of Clinical Nutrition 84, 725-731.

Le DS, Pannacciulli N, Chen K, Salbe AD, Del Parigi A, Hill JO, Wing RR, Reiman EM and Krakoff J 2007. Less activation in the left dorsolateral prefrontal cortex in the reanalysis of the response to a meal in obese than in lean women and its 
Val-Laillet

association with successful weight loss. The American Journal of Clinical Nutrition 86, 573-579.

Le Bourgot C, Ferret-Bernard S, Blat S, Apper E and Le Huërou-Luron I 2016. Short-chain fructooligosaccharide supplementation during gestation and lactation or after weaning differentially impacts pig growth and $\lg A$ response to influenza vaccination. Journal of Functional Foods 24, 307-315.

Le Bourgot C, Ferret-Bernard S, Le Normand L, Savary G, Menendez-Aparicio E, Blat S, Appert-Bossard E, Respondek F and Le Huerou-Luron I 2014. Maternal short-chain fructooligosaccharide supplementation influences intestinal immune system maturation in piglets. PLoS ONE 9, e107508.

Le Bourgot C, Le Normand L, Formal M, Respondek F, Blat S, Apper E, Ferret-Bernard $S$ and Le Huerou-Luron I 2017. Maternal short-chain fructooligosaccharide supplementation increases intestinal cytokine secretion, goblet cell number, butyrate concentration and Lawsonia intracellularis humoral vaccine response in weaned pigs. British Journal of Nutrition 117, 83-92.

Lee L, Alloosh M, Saxena R, Van Alstine W, Watkins BA, Klaunig JE, Sturek M and Chalasani N 2009. Nutritional model of steatohepatitis and metabolic syndrome in the Ossabaw miniature swine. Hepatology 50, 56-67.

Legeza B, Marcolongo P, Gamberucci A, Varga V, Banhegyi G, Benedetti A and Odermatt A 2017. Fructose, glucocorticoids and adipose tissue: implications for the metabolic syndrome. Nutrients 9, pii: E426.

Lind NM, Moustgaard A, Jelsing J, Vajta G, Cumming P and Hansen AK 2007. The use of pigs in neuroscience: modeling brain disorders. Neuroscience \& Biobehavioral Reviews 31, 728-751.

Lindqvist A, Ekelund M, Garcia-Vaz E, Stahlman M, Pierzynowski S, Gomez MF Rehfeld JF, Groop L, Hedenbro J, Wierup N and Spegel P 2017a. The impact of Roux-en-Y gastric bypass surgery on normal metabolism in a porcine model. PLOS ONE 12, e0173137.

Lindqvist A, Ekelund M, Pierzynowski S, Groop L, Hedenbro J and Wierup N 2017b. Gastric bypass in the pig increases GIP levels and decreases active GLP-1 levels. Peptides 90, 78-82.

Lindqvist A, Spegel P, Ekelund M, Garcia Vaz E, Pierzynowski S, Gomez MF, Mulder H, Hedenbro J, Groop L and Wierup N 2014. Gastric bypass improves beta-cell function and increases beta-cell mass in a porcine model. Diabetes 63, 1665-1671.

Lupoli R, Lembo E, Saldalamacchia G, Avola CK, Angrisani L and Capaldo B 2017. Bariatric surgery and long-term nutritional issues. World Journal of Diabetes 8, 464-474.

Madsen MB, Birck MM, Fredholm M and Cirera S 2010. Expression studies of the obesity candidate gene FTO in pig. Animal Biotechnology 21, 51-63.

Malbert CH, Bobillier E, Picq C, Divoux JL, Guiraud D and Henry C 2017a. Effects of chronic abdominal vagal stimulation of small-diameter neurons on brain metabolism and food intake. Brain Stimulation 10, 735-743.

Malbert CH, Picq C, Divoux JL, Henry C and Horowitz M 2017b. Obesityassociated alterations in glucose metabolism are reversed by chronic bilateral stimulation of the abdominal vagus nerve. Diabetes 66, 848-857.

McGuire W, Dyson L and Renfrew M 2010. Maternal obesity: consequences for children, challenges for clinicians and carers. Seminars in Fetal \& Neonatal Medicine 15, 108-112.

McNamara RK, Able J, Jandacek R, Rider T, Tso P, Eliassen JC, Alfieri D, Weber W, Jarvis K, DelBello MP, Strakowski SM and Adler CM 2010. Docosahexaenoic acid supplementation increases prefrontal cortex activation during sustained attention in healthy boys: a placebo-controlled, dose-ranging, functional magnetic resonance imaging study. The American Journal of Clinical Nutrition 91 , 1060-1067.

Menneson S, Ménicot $S$, Ferret-Bernard S, Guérin S, Romé $V$, Le Normand L, Randuineau G, Gambarota G, Noirot V, Etienne P, Coquery N and Val-Laillet D 2019. Validation of a psychosocial stress model in the pig using a multidisciplinary approach at the gut-brain and behavior levels. Frontiers in Behavioral Neuroscience 13, 161 .

Moretti M, Valvassori SS, Varela RB, Ferreira CL, Rochi N, Benedet J, Scaini G, Kapczinski F, Streck EL, Zugno Al and Quevedo J 2011. Behavioral and neurochemical effects of sodium butyrate in an animal model of mania. Behavioural Pharmacology 22, 766-772.

Mudd AT and Dilger RN 2017. Early-life nutrition and neurodevelopment: use of the piglet as a translational model. Advances in Nutrition 8, 92-104.

Mudd AT, Getty CM and Dilger RN 2018. Maternal dietary choline status influences brain gray and white matter development in young pigs. Current Developments in Nutrition 2, nzy015.
Mudd AT, Getty CM, Sutton BP and Dilger RN 2016. Perinatal choline deficiency delays brain development and alters metabolite concentrations in the young pig. Nutritional Neuroscience 19, 425-433.

Myles IA, Fontecilla NM, Janelsins BM, Vithayathil PJ, Segre JA and Datta SK 2013. Parental dietary fat intake alters offspring microbiome and immunity. The Journal of Immunology 191, 3200-3209.

Obrenovich M, Fluckiger R, Sykes L and Donskey C 2016. The co-metabolism within the gut-brain metabolic interaction: potential targets for drug treatment and design. CNS \& Neurological Disorders-Drug Targets 15, 127-134.

Ochner CN, Kwok Y, Conceicao E, Pantazatos SP, Puma LM, Carnell S, Teixeira J, Hirsch $J$ and Geliebter A 2011. Selective reduction in neural responses to high calorie foods following gastric bypass surgery. Annals of Surgery 253 502-507.

Ochoa M, Lalles JP, Malbert CH and Val-Laillet D 2015. Dietary sugars: their detection by the gut-brain axis and their peripheral and central effects in health and diseases. European Journal of Nutrition 54, 1-24.

Ochoa M, Malbert CH, Lalles JP, Bobillier E and Val-Laillet D 2014. Effects of chronic intake of starch-, glucose- and fructose-containing diets on eating behaviour in adult minipigs. Applied Animal Behaviour Science 157, 61-71.

Ochoa M, Malbert CH, Meurice P and Val-Laillet D 2016a. Effects of chronic consumption of sugar-enriched diets on brain metabolism and insulin sensitivity in adult Yucatan minipigs. PLoS ONE 11, e0161228.

Ochoa M, Val-Laillet D, Lalles JP, Meurice P and Malbert CH 2016b. Obesogenic diets have deleterious effects on fat deposits irrespective of the nature of dietary carbohydrates in a Yucatan minipig model. Nutrition Research 36, 947-954.

Parker G, Gibson NA, Brotchie H, Heruc G, Rees AM and Hadzi-Pavlovic D 2006. Omega-3 fatty acids and mood disorders. American Journal of Psychiatry 163, 969-978.

Phillips RW, Westmoreland N, Panepinto L and Case GL 1982. Dietary effects on metabolism of Yucatan miniature swine selected for low and high glucose utilization. Journal of Nutrition 112, 104-111.

Pinto-Sanchez MI, Hall GB, Ghajar K, Nardelli A, Bolino C, Lau JT, Martin FP, Cominetti O, Welsh C, Rieder A, Traynor J, Gregory C, De Palma G, Pigrau M, Ford AC, Macri J, Berger B, Bergonzelli G, Surette MG, Collins SM, Moayyedi P and Bercik P 2017. Probiotic Bifidobacterium longum NCC3001 reduces depression scores and alters brain activity: a pilot study in patients with irritable bowel syndrome. Gastroenterology 153, 448-459.e8.

Potvin M, Gagner M and Pomp A 1997. Laparoscopic Roux-en-Y gastric bypass for morbid obesity: a feasibility study in pigs. Surgical Laparoscopy Endoscopy \& Percutaneous Techniques 7, 294-297.

Rao RS, Rao V and Kini S 2010. Animal models in bariatric surgery - a review of the surgical techniques and postsurgical physiology. Obesity Surgery 20, 1293-1305.

Rizkalla SW 2010. Health implications of fructose consumption: a review of recent data. Nutrition \& Metabolism (London) 7, 82.

Roura E, Koopmans SJ, Lalles JP, Le Huerou-Luron I, de Jager N, Schuurman T and Val-Laillet D 2016. Critical review evaluating the pig as a model for human nutritional physiology. Nutrition Research Reviews 29, 60-90.

Saikali S, Meurice P, Sauleau P, Eliat PA, Bellaud P, Randuineau G, Verin M and Malbert CH 2010. A three-dimensional digital segmented and deformable brain atlas of the domestic pig. Journal of Neuroscience Methods 192, 102-109.

Sauleau P, Lapouble E, Val-Laillet D and Malbert CH 2009. The pig model in brain imaging and neurosurgery. Animal 3, 1138-1151.

Scholtz S, Miras AD, Chhina N, Prechtl CG, Sleeth ML, Daud NM, Ismail NA Durighel G, Ahmed AR, Olbers T, Vincent RP, Alaghband-Zadeh J, Ghatei MA, Waldman AD, Frost GS, Bell JD, le Roux CW and Goldstone AP 2014. Obese patients after gastric bypass surgery have lower brain-hedonic responses to food than after gastric banding. Gut 63, 891-902.

Sclafani A and Ackroff K 2012. Role of gut nutrient sensing in stimulating appetite and conditioning food preferences. American Journal of Physiology. Regulatory, Integrative and Comparative Physiology 302, R1119-R1133.

Sefcikova Z, Bujnakova D, Racek L, Kmet V and Mozes S 2011. Developmental changes in gut microbiota and enzyme activity predict obesity risk in rats arising from reduced nests. Physiological Research 60, 337-346.

Sham JG, Simianu VV, Wright AS, Stewart SD, Alloosh M, Sturek M, Cummings DE and Flum DR 2014. Evaluating the mechanisms of improved glucose homeostasis after bariatric surgery in Ossabaw miniature swine. Journal of Diabetes Research 2014, 526972. 
Steiner JE, Glaser D, Hawilo ME and Berridge KC 2001. Comparative expression of hedonic impact: affective reactions to taste by human infants and other primates. Neuroscience \& Biobehavioral Reviews 25, 53-74.

Stice E, Figlewicz DP, Gosnell BA, Levine AS and Pratt WE 2013. The contribution of brain reward circuits to the obesity epidemic. Neuroscience \& Biobehavioral Reviews 37, 2047-2058.

Thanos PK, Michaelides M, Gispert JD, Pascau J, Soto-Montenegro ML, Desco M Wang R, Wang GJ and Volkow ND 2008. Differences in response to food stimuli in a rat model of obesity: in-vivo assessment of brain glucose metabolism. International Journal of Obesity (London) 32, 1171-1179.

Val-Laillet $D$, Aarts $E$, Weber $B$, Ferrari $M$, Quaresima V, Stoeckel $L E$, Alonso-Alonso M, Audette M, Malbert CH and Stice E 2015. Neuroimaging and neuromodulation approaches to study eating behavior, prevent and treat eating disorders and obesity. Neuroimage: Clinical 24, 1-31.

Val-Laillet D, Besson M, Guerin S, Coquery N, Randuineau G, Kanzari A, Quesnel H, Bonhomme N, Bolhuis JE, Kemp B, Blat S, Le Huerou-Luron I and Clouard C 2017. A maternal western diet during gestation and lactation modifies offspring's microbiota activity, blood lipid levels, cognitive responses, and hippocampal neurogenesis in Yucatan pigs. The FASEB Journal 31, 2037-2049.

Val-Laillet D, Biraben A, Randuineau G and Malbert CH 2010a. Chronic vagus nerve stimulation decreased weight gain, food consumption and sweet craving in adult obese minipigs. Appetite $55,245-252$.

Val-Laillet D, Blat S, Louveau I and Malbert CH 2010b. A computed tomography scan application to evaluate adiposity in a minipig model of human obesity. British Journal of Nutrition 104, 1719-1728.

Val-Laillet D, Guerin S, Coquery N, Nogret I, Formal M, Rome V, Le Normand L, Meurice $P$, Randuineau $G$, Guilloteau P, Malbert $\mathrm{CH}$, Parnet $\mathrm{P}$, Lalles JP and Segain JP 2018. Oral sodium butyrate impacts brain metabolism and hippocampal neurogenesis, with limited effects on gut anatomy and function in pigs. The FASEB Journal 32, 2160-2171.

Val-Laillet D, Guerin S and Malbert CH 2010c. Slower eating rate is independent to gastric emptying in obese minipigs. Physiology \& Behavior 101, 462-468.

Val-Laillet D, Layec S, Guerin S, Meurice P and Malbert CH 2011a. Changes in brain activity after a diet-induced obesity. Obesity (Silver Spring) 19, 749-756.

Val-Laillet D, Meurice P and Clouard C 2016. Familiarity to a feed additive modulates its effects on brain responses in reward and memory regions in the pig model. PLOS ONE 11, e0162660.
Val-Laillet D, Meurice P, Lalles JP and Malbert CH 2011b. Central functions altered by chronic high-lipids diets enriched with omega-3, omega- 6 or saturated fat. Proceedings of the Nutrition Society 70 , E369-E369.

Val-Laillet D, Meurice P, Lalles JP and Malbert CH 2013. Central functions altered by chronic high-lipids diets enriched with omega-3, omega- 6 or saturated fat. Gastroenterology 144, S837-S837.

Valvassori SS, Varela RB, Arent CO, Dal-Pont GC, Bobsin TS, Budni J, Reus GZ and Quevedo J 2014. Sodium butyrate functions as an antidepressant and improves cognition with enhanced neurotrophic expression in models of maternal deprivation and chronic mild stress. Current Neurovascular Research 11, 359-366.

van de Wouw M, Schellekens H, Dinan TG and Cryan JF 2017 Microbiota-gut-brain axis: modulator of host metabolism and appetite. Journal of Nutrition 147, 727-745.

Volkow ND, Wang GJ, Telang F, Fowler JS, Goldstein RZ, Alia-Klein N, Logan J, Wong C, Thanos PK, Ma Y and Pradhan K 2009. Inverse association between BMI and prefrontal metabolic activity in healthy adults. Obesity (Silver Spring) 17 60-65.

Volkow ND, Wang GJ, Telang F, Fowler JS, Thanos PK, Logan J, Alexoff D, Ding YS, Wong C, Ma Y and Pradhan K 2008. Low dopamine striatal D2 receptors are associated with prefrontal metabolism in obese subjects: possible contributing factors. Neuroimage 42, 1537-1543.

Vonck K, De Herdt V and Boon P 2009. Vagal nerve stimulation - a 15-year survey of an established treatment modality in epilepsy surgery. Advances and Technical Standards in Neurosurgery 34, 111-146.

Wang GJ, Volkow ND, Logan J, Pappas NR, Wong CT, Zhu W, Netusil N and Fowler JS 2001. Brain dopamine and obesity. Lancet 357, 354-357.

Wang YS, Zhou P, Liu H, Li S, Zhao Y, Deng K, Cao DD, Che LQ, Fang ZF, Xu SY, Lin Y, Feng B, Li J and Wu D 2016. Effects of inulin supplementation in low- or high-fat diets on reproductive performance of sows and antioxidant defence capacity in sows and offspring. Reproduction in Domestic Animals 51, 492-500.

Williams L, Seki Y, Vuguin PM and Charron MJ 2014. Animal models of in utero exposure to a high fat diet: a review. Biochimica et Biophysica Acta $1842,507-519$. 